\title{
Sensitivity Analysis of Fourier Transformation Spectrometer: FTS Against Observation Noise on Retrievals of Carbon Dioxide and Methane
}

\author{
Kohei Arai \\ Graduate School of Science and Engineering \\ Saga University \\ Saga City, Japan \\ Takuya Fukamachi \\ Graduate School of Science and Engineering \\ Saga University \\ Saga City, Japan
}

\author{
Hiroshi Okumura \\ Graduate School of Science and Engineering \\ Saga University \\ Saga City, Japan \\ Shuji Kawakami \\ JAXA, Japan \\ Tsukuba City, Japan
}

\author{
HirofumiOhyama \\ JAXA, Japan \\ Tsukuba City, Japan
}

\begin{abstract}
Sensitivity analysis of Fourier Transformation Spectrometer: FTS against observation noise on retrievals of carbon dioxide and methane is conducted. Through experiments with real observed data and additive noise, it is found that the allowable noise on FTS observation data is less than $2.1 \times 10^{-5}$ if estimation accuracy of total column carbon dioxide and methane is better than $1(\%)$.
\end{abstract}

Keywords-FTS; carbon dioxide, methane, sensitivity analysis, error analysis.

\section{INTRODUCTION}

Greenhouse gases Observing SATellite: GOSATcarries TANSO CAI for clouds and aerosol particles observation of mission instrument and TANSO FTS ${ }^{1}$ : Fourier Transformation Spectrometer ${ }^{2}$ for carbon dioxide and methane retrieving mission instrument [1]. In order to verify the retrieving accuracy of two mission instruments, ground based laser radar and TANSO FTS are installed. The former is for TANSO CAI and the latter is for FTS, respectively. One of the other purposes of the ground-based laser radar and the ground-based FTS is to check sensor specifications for the future mission of instruments to be onboard future satellite with extended mission. Although the estimation methods for carbon dioxide and methane are well discussed [2]-[6], estimation method which takes into account measurement noise is not analyzed

\footnotetext{
${ }^{1}$ http://www.jaxa.jp/projects/sat/gosat/index_j.html

http://ja.wikipedia.org/wiki/\%E3\%83\%9E\%E3\%82\%A4\%E3\%82\%B1\%E3\% 83\%AB\%E3\%82\%BD\%E3\%83\%B3\%Е5\%B9\%B2\%E6\%B8\%89\%Е8\%A8 $\% 88$
}

yet. Therefore, error analysis for additive noise on estimation accuracy is conducted.

In order to clarify requirement of observation noises to be added on the ground-based FTS observation data, Sensitivity analysis of the ground-based FTS against observation noise on retrievals of carbon dioxide and methane is conducted. Experiments are carried out with additive noise on the real acquired data of the ground-based FTS. Through retrievals of total column of carbon dioxide and methane with the noise added the ground-based FTS signals, retrieval accuracy is evaluated. Then an allowable noise on the ground-based FTS which achieves the required retrieval accuracy (1\%) is reduced.

The following section describes the proposed sensitivity analysis followed by some experiments. Then concluding remarks with some discussions is followed by.

\section{PROPOSED SENSITIVITY ANALYSIS}

\section{A. Ground-based FTS}

Figure 1 shows schematic configuration of the groundbased FTS which is originated from Michelson Interference Measurement Instrument. Light from the light source divided in to two directions, the left and the forward at the dichotic mirror of half mirror. The left light is reflected at the fixed hold mirror and reaches to the half mirror while the forward light is reflected at the moving mirror and reaches at the half mirror. Then interference occurs between the left and the forward lights. After that interference light is detected by detector. Outlook of the ground-based FTS is shown in Figure2. 
Figure 3 (a) shows an example of the interferogram ${ }^{3}$ (interference light detected by the detector of the ground-based FTS). By applying Fourier Transformation to the interferogram, observed Fourier spectrum is calculated as shown in Figure 3 (b). When the ground-based FTS observes the atmosphere, the observed Fourier spectrum includes absorptions due to atmospheric molecules and aerosol particles. By comparing to the spectrum which is derived from the radiative transfer code with atmospheric parameters, atmospheric molecules and aerosol particles are estimated.

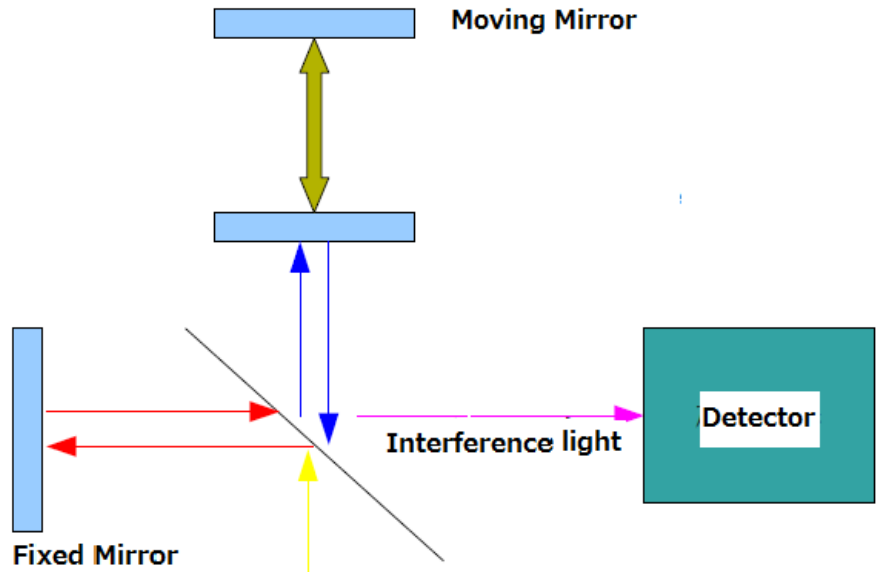

Half Mirror

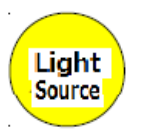

Figure 1 Michelson Interference Measurement Instrument

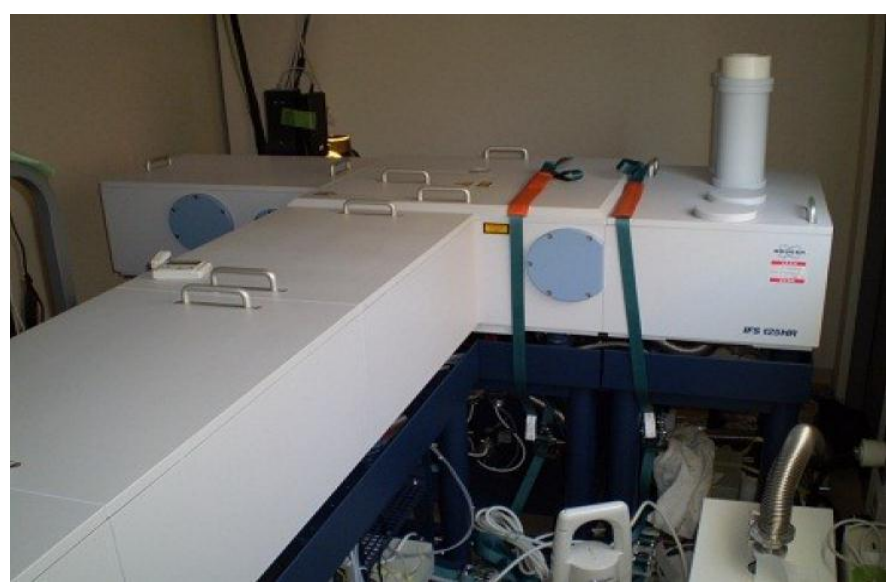

Figure 2 Outlook of the FTS used

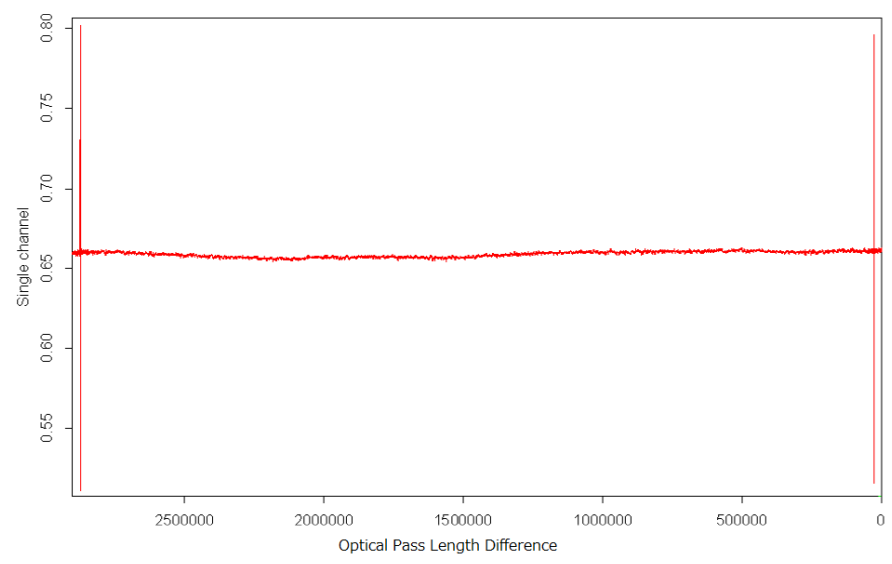

(a)Interferogram

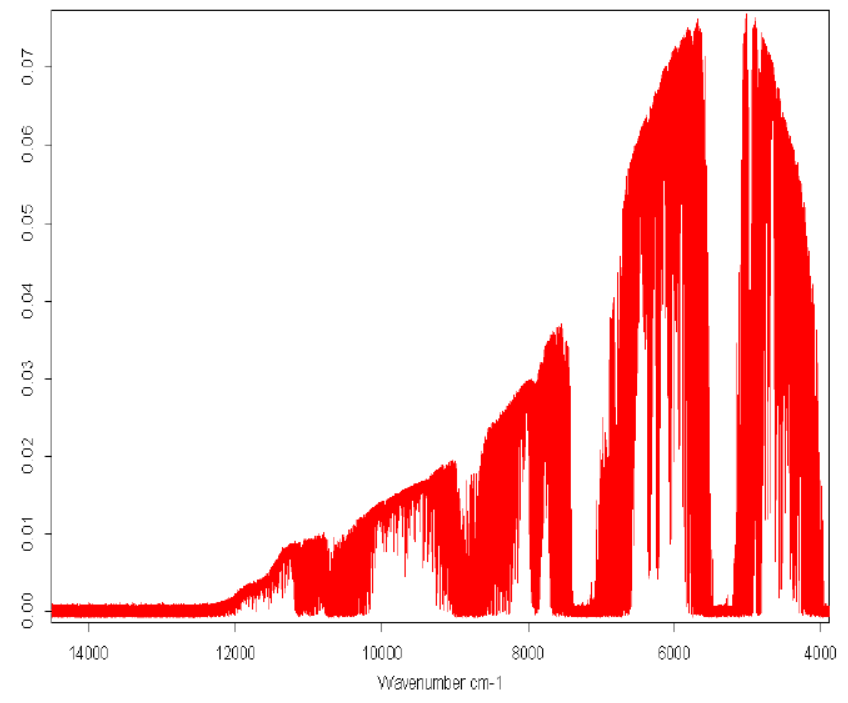

(b)Fourier spectrum

Figure 3 Examples of interferogram and Fourier spectrum when FTS observes the atmosphere

\section{B. Principle for Carbon Dioxide and Methane Retrievals with TANSO FTS Data}

Figure 4 shows a principle of the retrieval method for atmospheric continuants using GOSAT/TANSO data. Figure 4 (a) shows Top of the Atmosphere: TOA radiance in the wavelength ranges from 500 to $2500 \mathrm{~nm}$ (visible to shortwave infrared wavelength regions). There are three major absorption bands due to oxygen (760-770nm), carbon dioxide and methane (1600-1700nm), and water vapor and carbon dioxide $(1950-2050 \mathrm{~nm})$ as shown in Figure 4 (b), (c), and (d), respectively. These bands are GOSAT/TANSO spectral bands, Band 1 to 3, respectively. In addition to these, there is another wide spectrum of spectral band, Band 4 as shown in Figure 4(e) which covers from visible to thermal infrared regions..

\footnotetext{
${ }^{3}$ http://en.wikipedia.org/wiki/Interferometry
} 


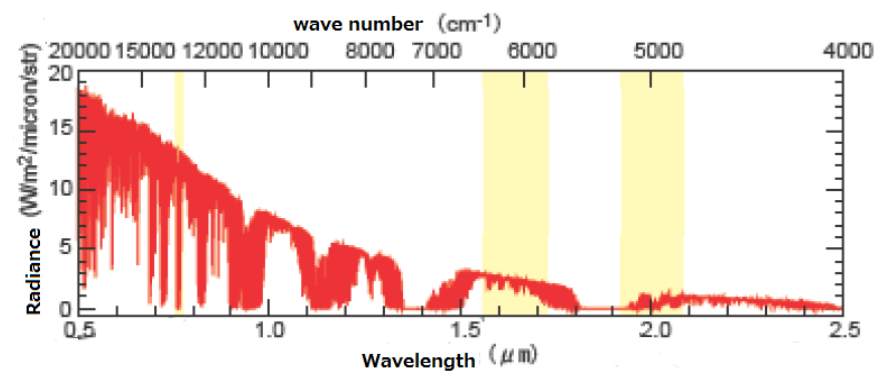

(a)TOA radiance

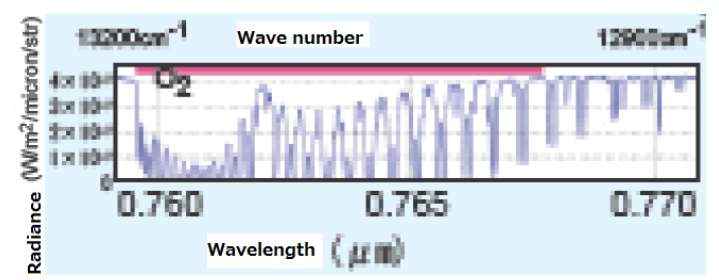

(b)Band 1

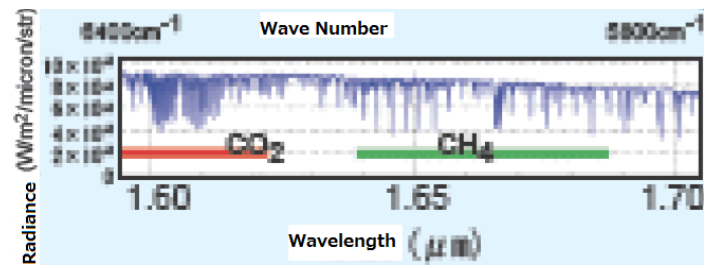

(c)Band 2

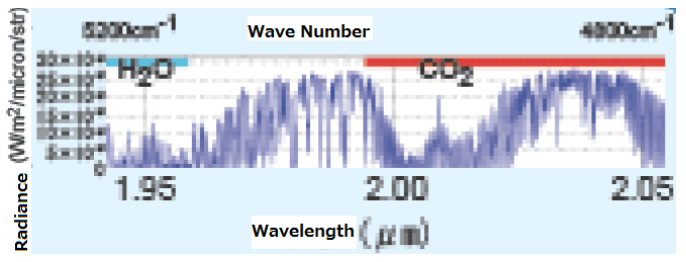

(d)Band 3

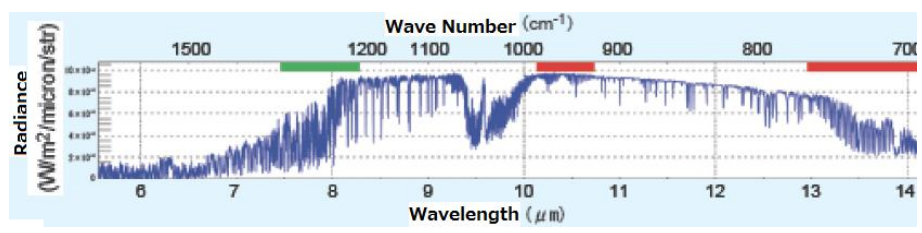

(e)Band 4

Figure 4 Example of TOA radiance and absorption bands as well as spectral bands of GOSAT/TANSO instrument

\section{EXPERIMENTS}

\section{A. Ground-based FTS Data Used}

The ground-based FTS data used for experiments are acquired on November 14 and December 19 2011. Figure 5 shows the interferograms derived from the acquired the ground-based FTS data.

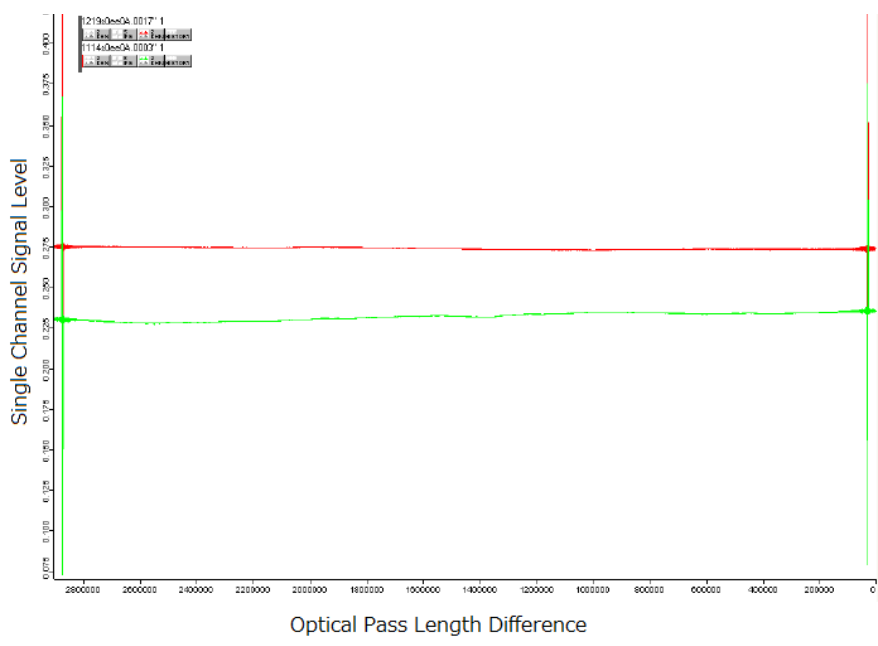

Figure 5 Example of interferograms used for experiments.

\section{B. Experimental Method}

Observation noise is included in the observed interferograms. In addition to the existing noise, several levels of additional noises which are generated by random number generator of Messene Twister with zero mean and several standard deviations is added on to the iterferograms as shown in Figure 6.

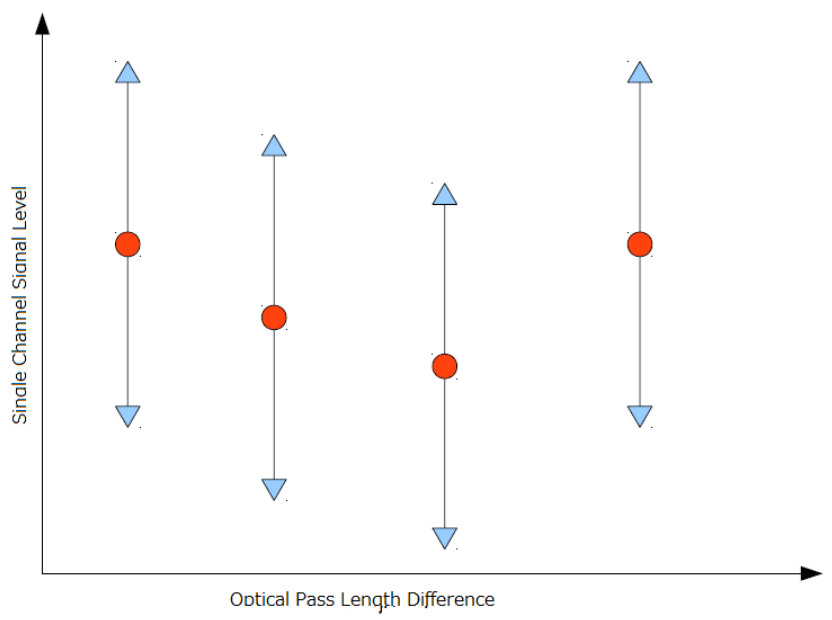

Figure 6 Method for adding the noises to the acquired interferograms

\section{Experimental Results(Noise Added Interferograms and Fourier Spectra)}

Figure 7 shows noise added interferograms and the Fourier spectra derived from the noise added interferograms.Added noises ranges from 0 to $1 \times 10^{-3}$. $1 / 1000$ of standard deviation of noise (zero mean) against signal level is added to the single channel of signal level in maximum. Vertical axis shows signal level and horizontal axis shows optical pass length difference for Figure 7 (a), (c), (e), (g), (i), (k), and (m) while vertical axis shows Fourier spectrum (amplitude) and horizontal axis shows frequncy (or wave number) for the rest of Figure 7. 
As shon in Figure 7, Fourier spectra is degrading in accordance with incresing of noise obviously. Although the additive noises are not clearly seen, it is slightly recognizable the noise through comparison between Figure (b) and (o).

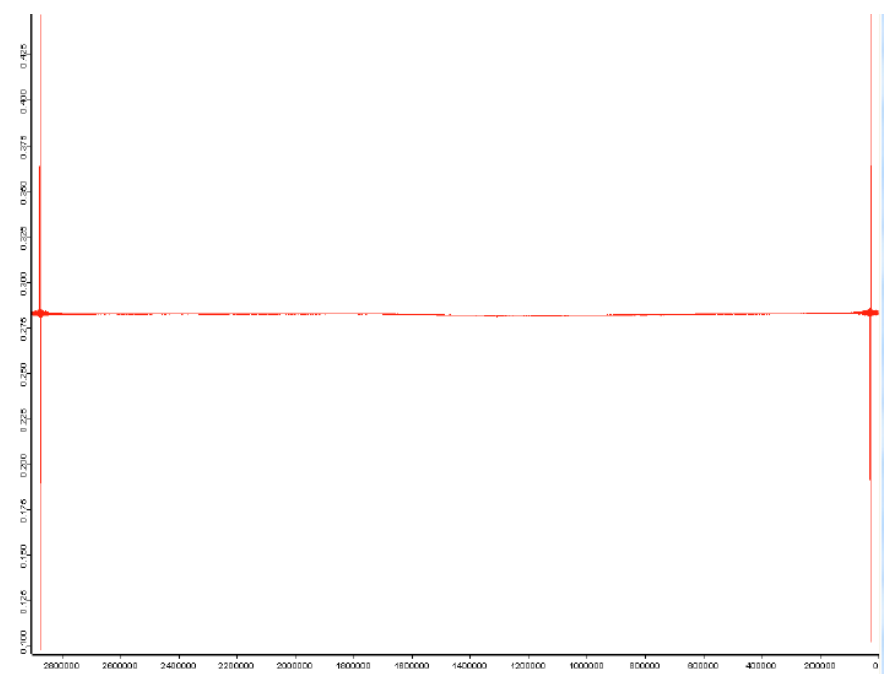

(a)Interferogram $(0)$

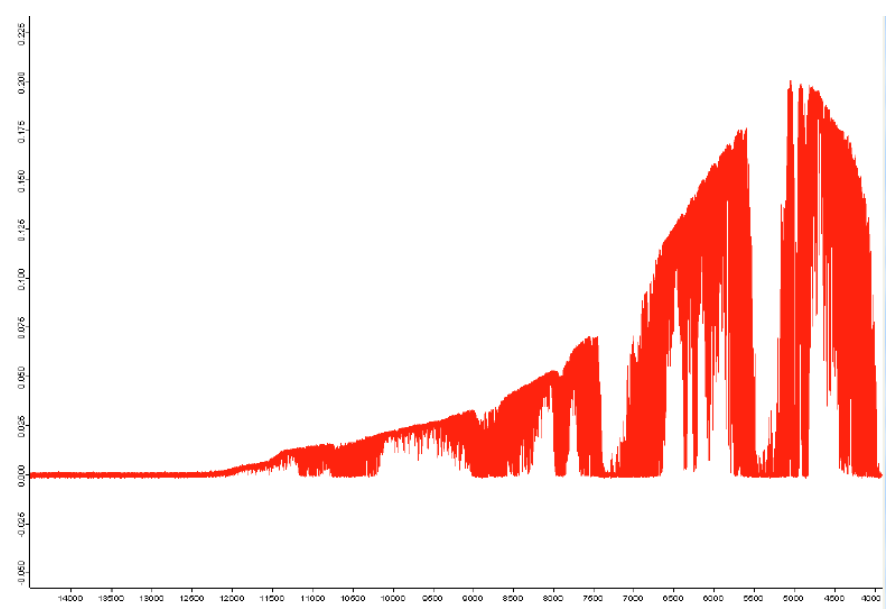

(b)Fourier spectrum(0)

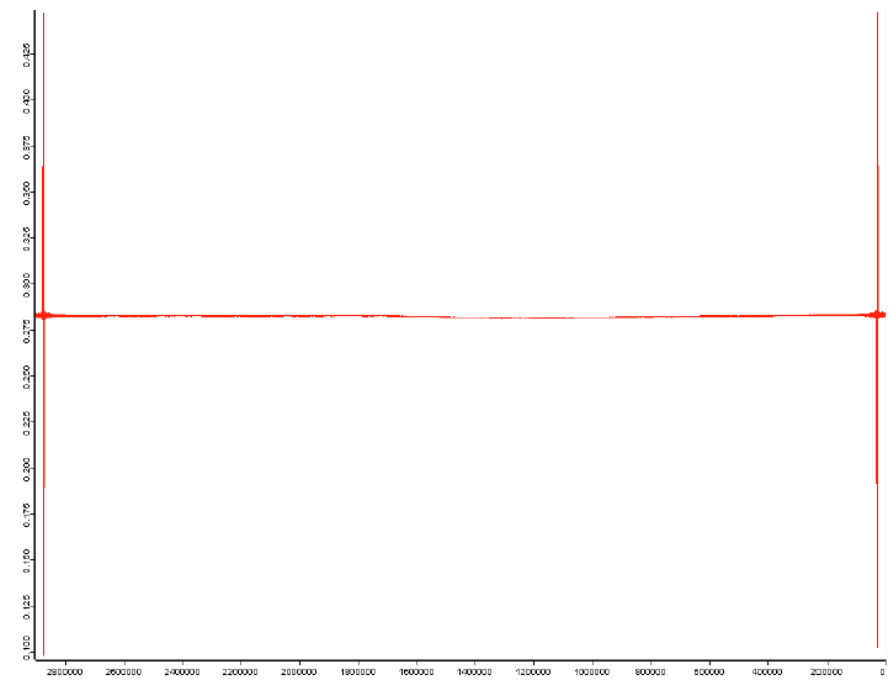

(c)Interferogram $\left(2.5 \times 10^{-5}\right)$

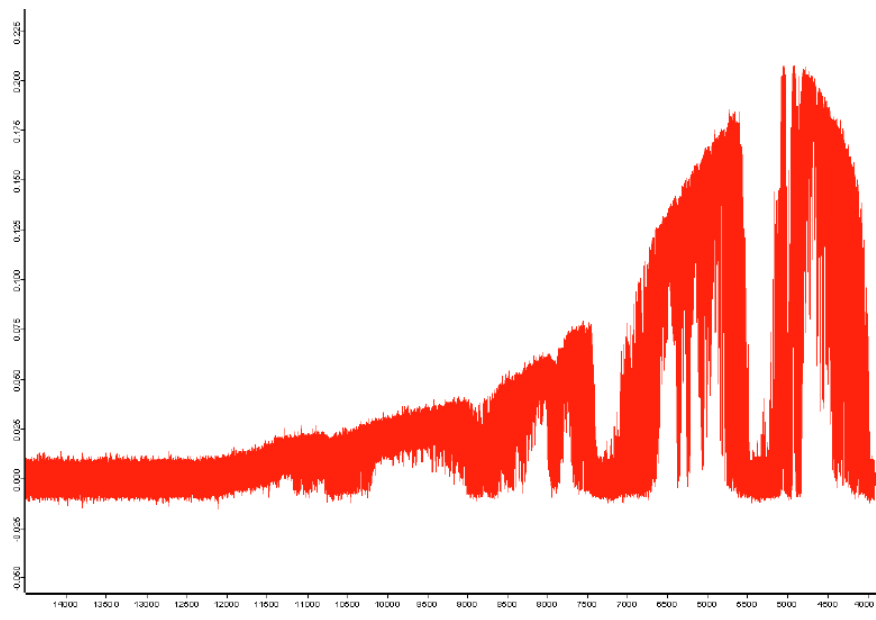

(d)Fourier $\operatorname{spectrum}\left(2.5 \times 10^{-5}\right)$

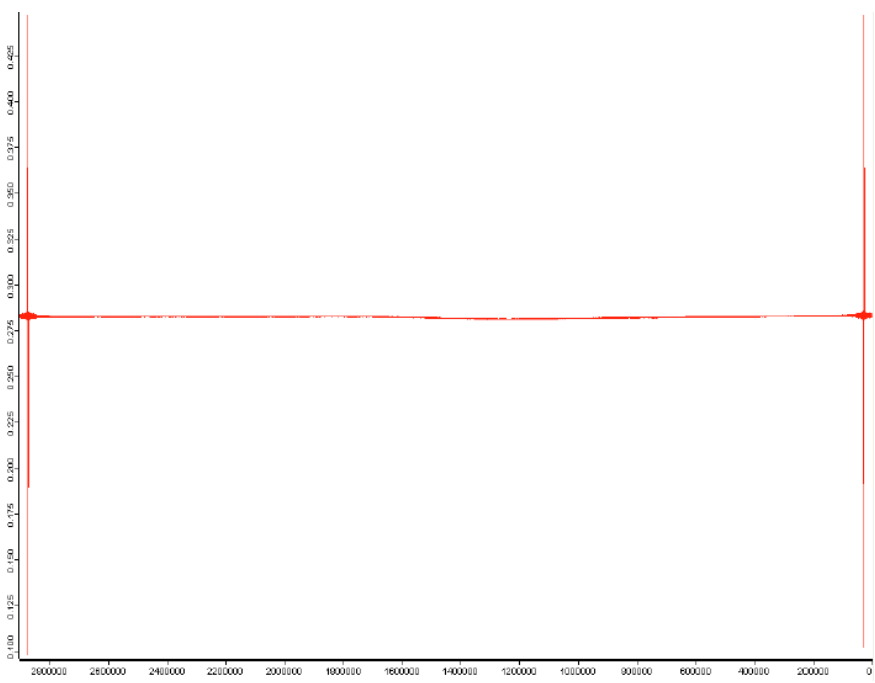

(e)Interferogram $\left(5 \times 10^{-5}\right)$

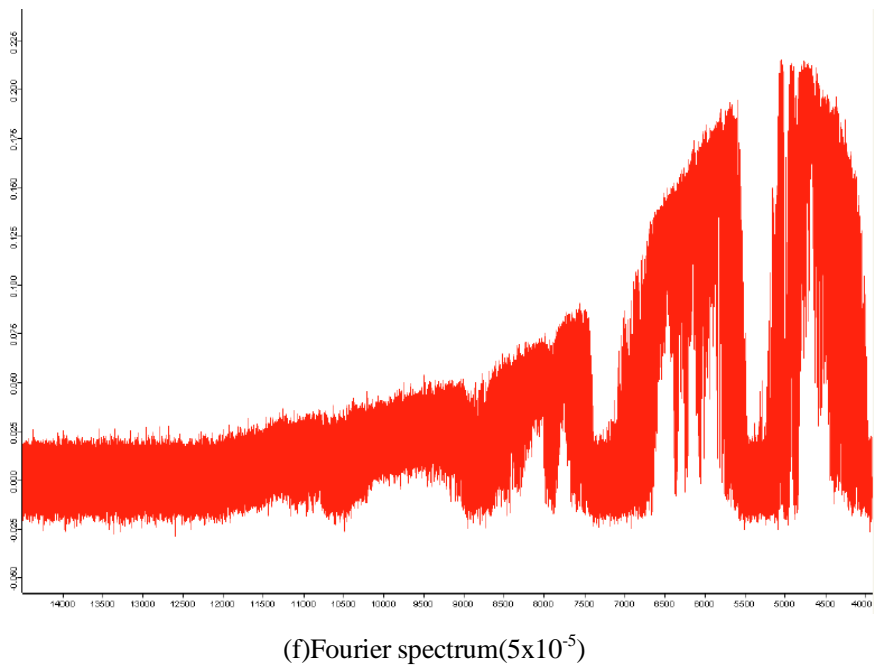



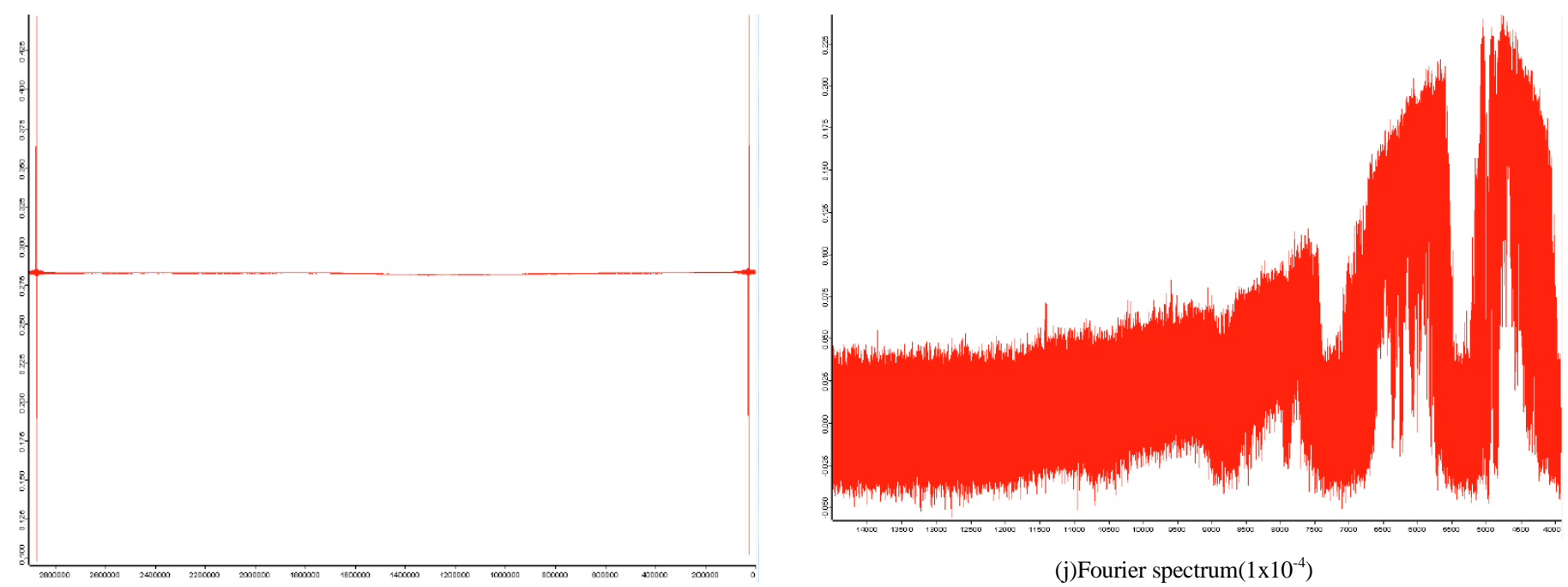

(g)Interferogram $\left(7.5 \times 10^{-5}\right)$

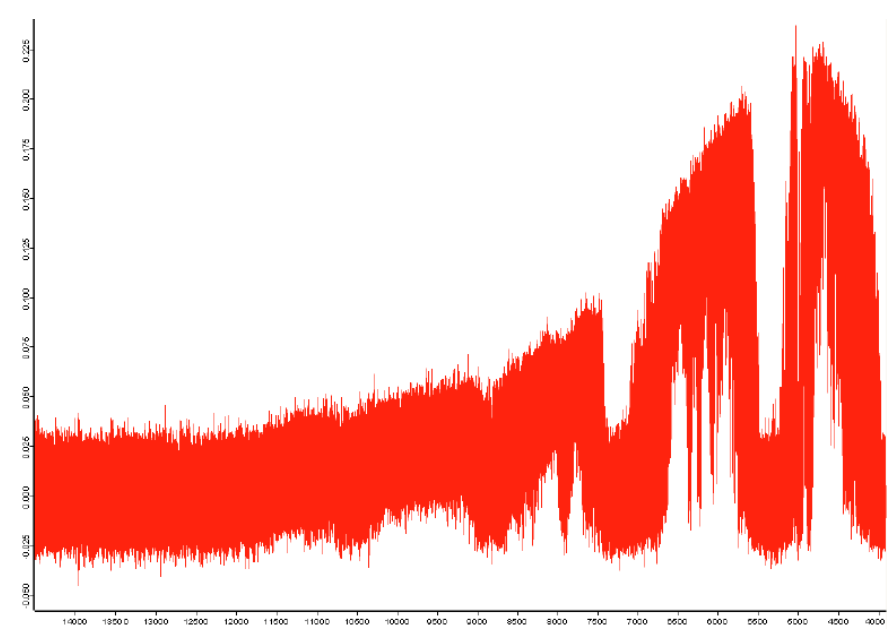

(j)Fourier spectrum $\left(1 \times 10^{-4}\right)$

(h)Fourier spectrum $\left(7.5 \times 10^{-5}\right)$

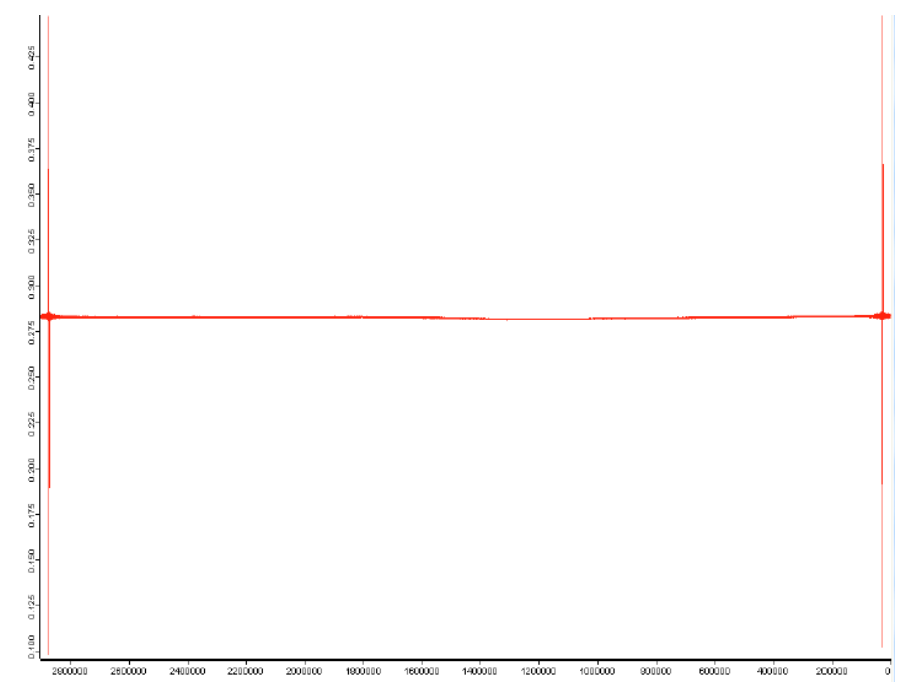

(k)Interferogram $\left(2 \times 10^{-4}\right)$
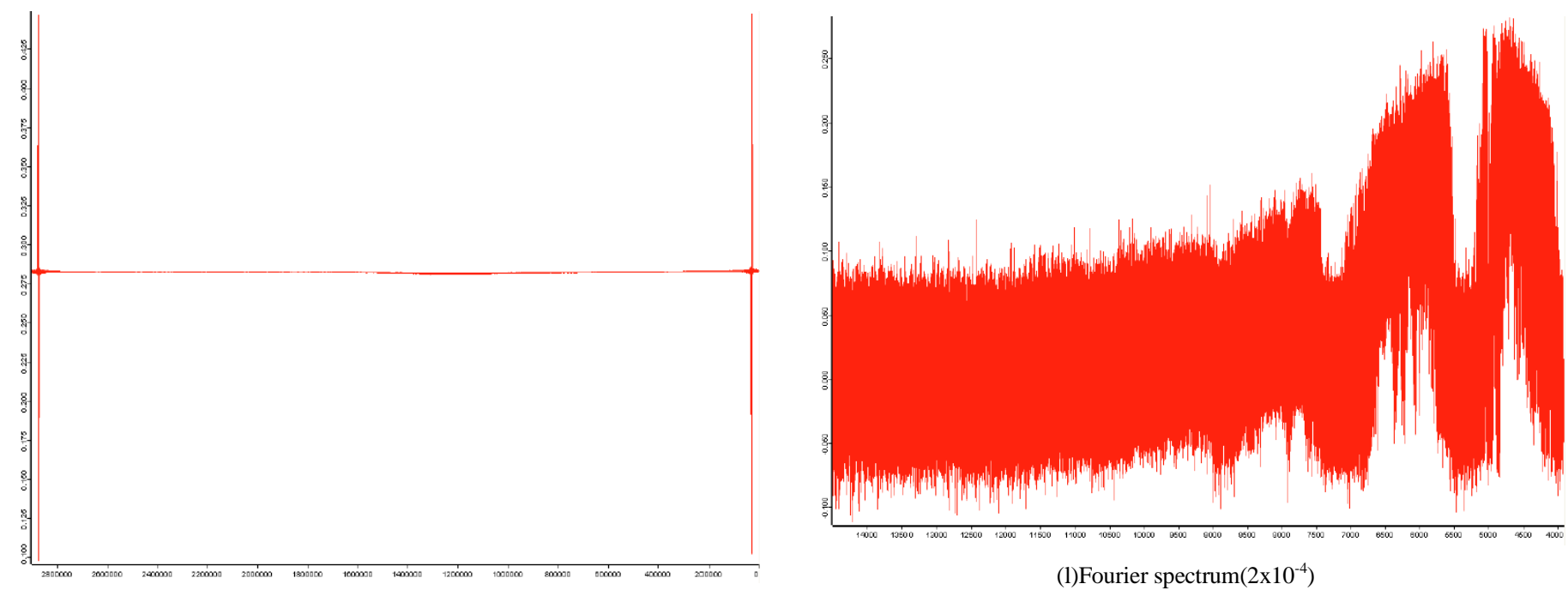

(i)Interferogram $\left(1 \times 10^{-4}\right)$

(1)Fourier spectrum $\left(2 \times 10^{-4}\right)$ 


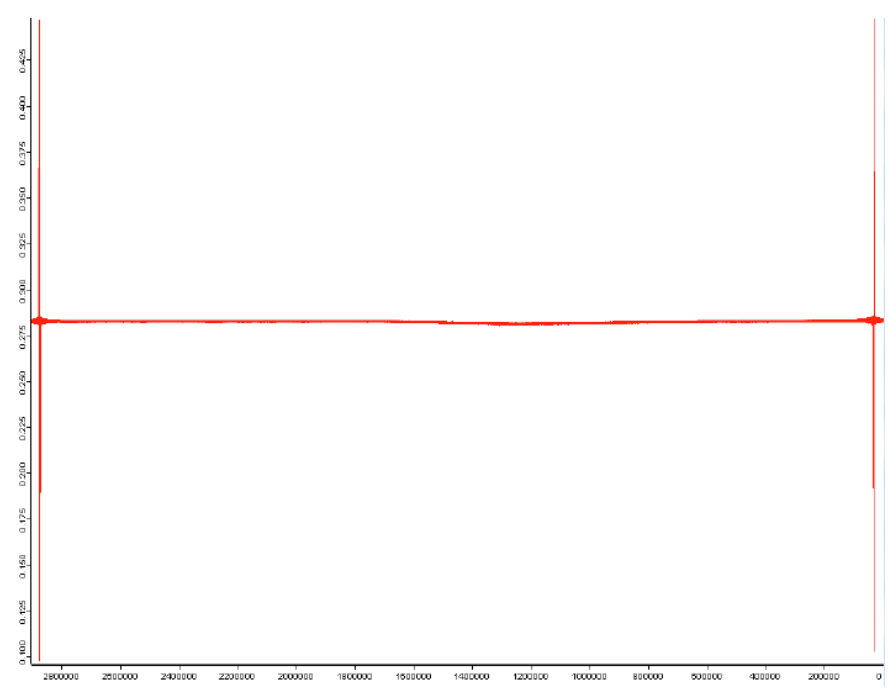

(m)Interferogram $\left(5 \times 10^{-4}\right)$

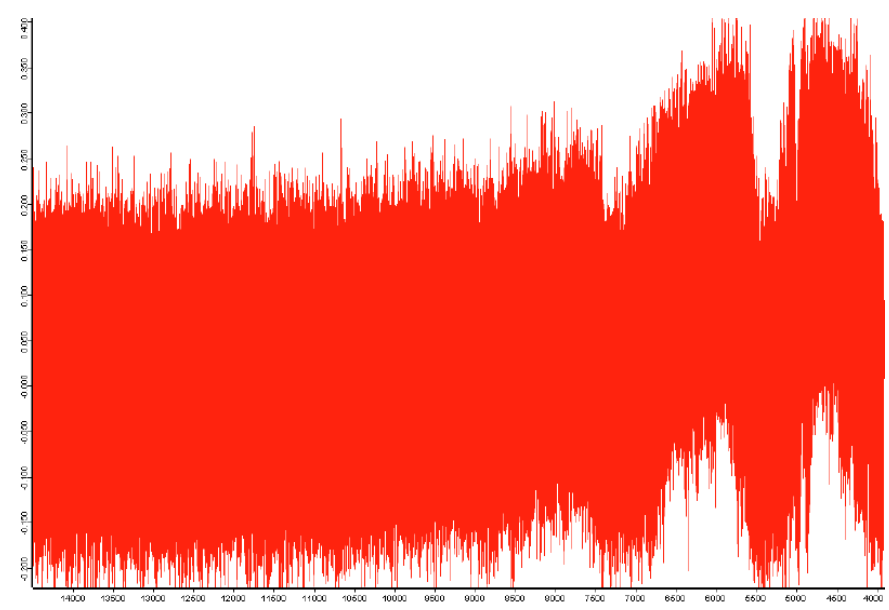

(n)Fourier $\operatorname{spectrum}\left(5 \times 10^{-4}\right)$

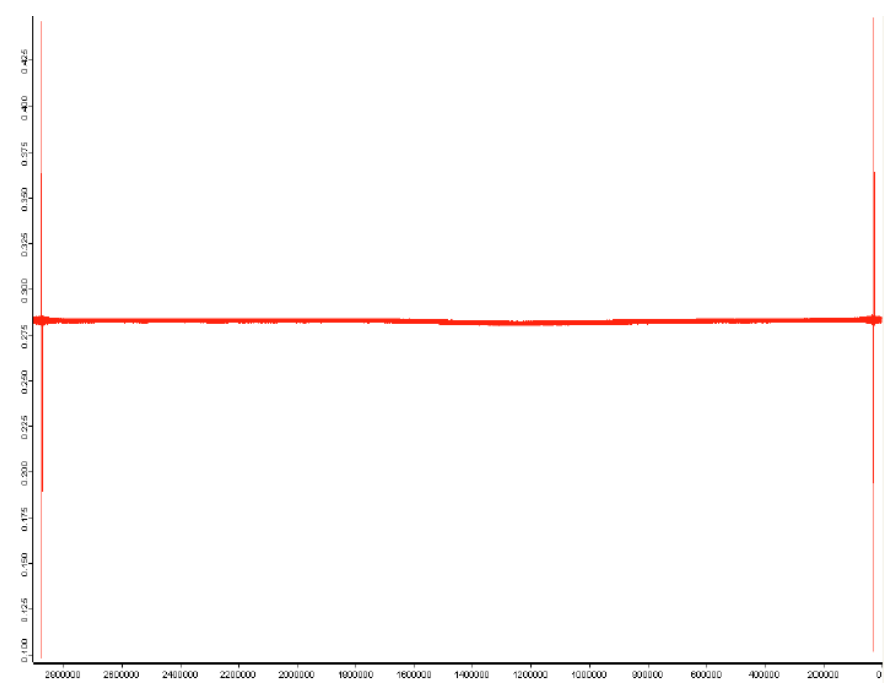

(o)Interferogram $\left(1 \times 10^{-3}\right)$

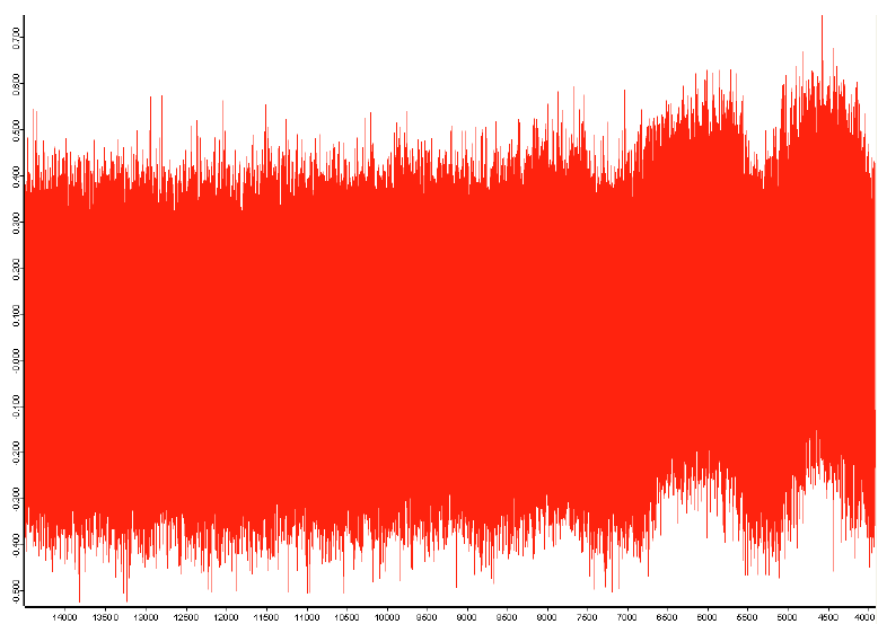

(p)Fourier spectrum $\left(1 \times 10^{-3}\right)$

Figure 7 Noise addediInterferograms and Fourier spectrum derived from the interferograms

\section{Experimental Results (Retrieval Error)}

Figure 8 (a) shows methane retrieved results. Horizontal axis shows standard deviation of additive noise and vertical axis shows retrieved methane amount in unit of ppm (percent per million). Figure 8 (b) shows retrieved error (retrieved methane amount from noise added interferogram minus retrieved methane amount from noise free interferogram).

Meanwhile, Figure 8 (c) shows carbon dioxide retrieved results. Horizontal axis shows standard deviation of additive noise and vertical axis shows retrieved carbon dioxide amount in unit of ppm (percent per million). Figure 8 (d) shows retrieved error (retrieved methane amount from noise added interferogram minus retrieved carbon dioxide amount from noise free interferogram). GFIT of retrieval software code is used for both estimations of total column carbon dioxide and methane contents in the atmosphere [6].

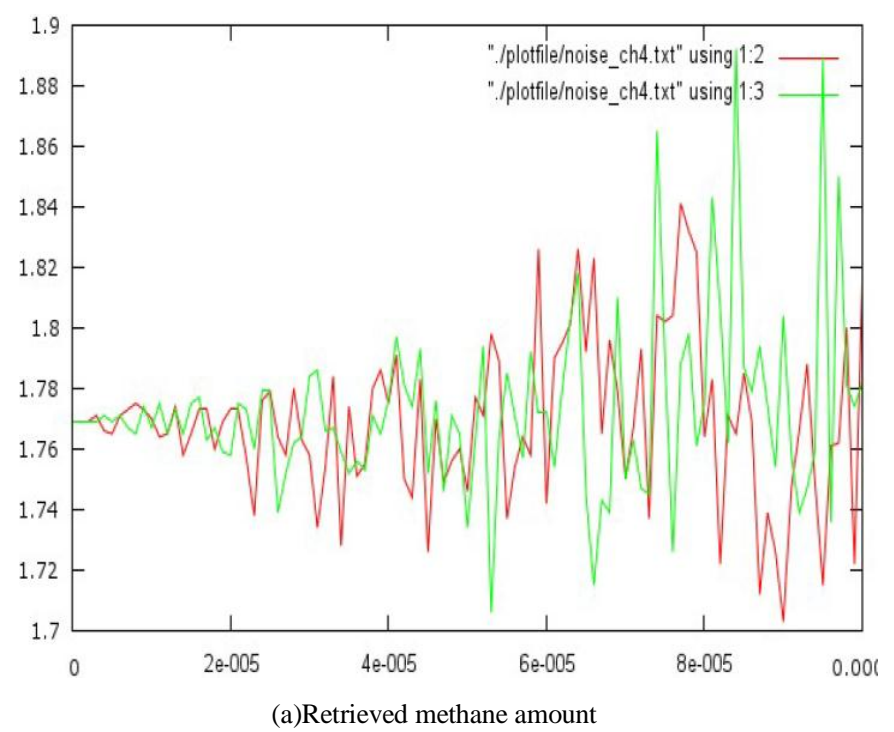




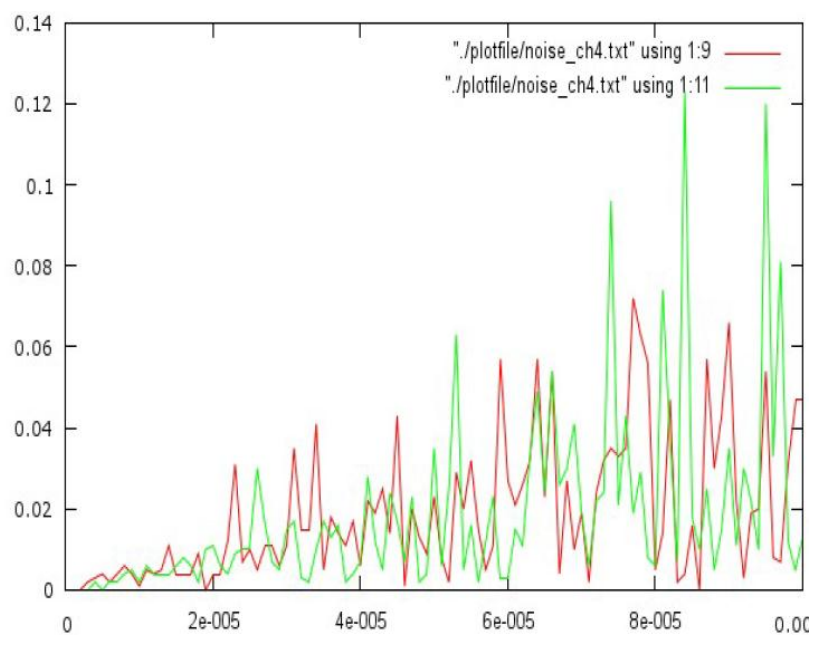

(b)Retrieved error

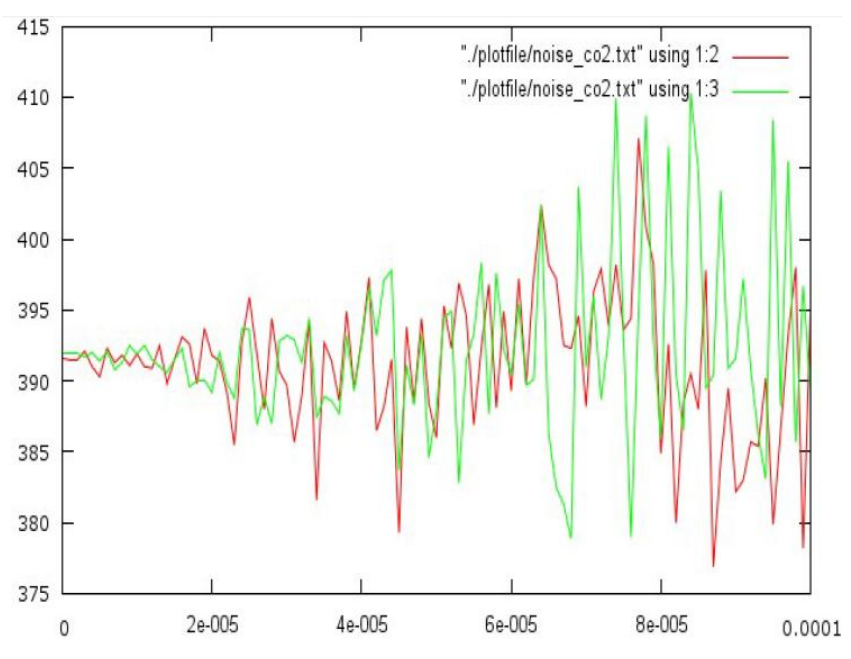

(c)Retrieved carbon dioxide amount

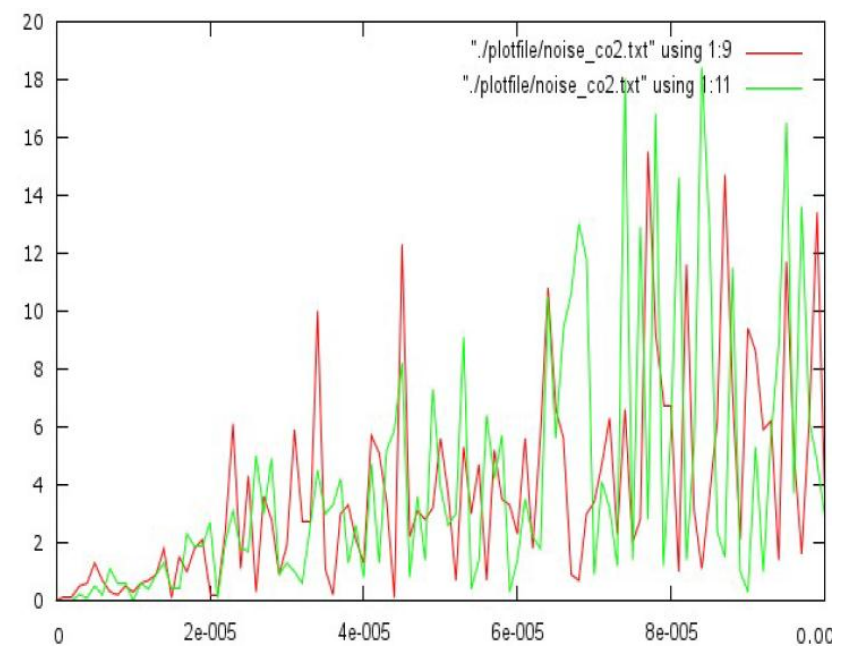

(d)Retrieved error
Figure 8 Retrieved carbon dioxide and methane amount with noise added and noise free iterferograms together with retrieved errors.

From these figures, it is concluded as follows,

Allowable retrieval errors for methane and carbon dioxide are $0.02 \mathrm{ppm}$ and $4 \mathrm{ppm}$, respectively. Therefore, acceptable noise level on FTS interferogram is less than $2.1 \times 10^{-5}$.

\section{CONCLUSION}

Sensitivity analysis of Fourier Transformation Spectrometer: FTS against observation noise on retrievals of carbon dioxide and methane is conducted. Through experiments with real observed data and additive noise, it is found that the allowable noise on FTS observation data is less than $2.1 \times 10^{-5}$ if estimation accuracy of total column carbon dioxide and methane is better than 1\% (allowable retrieval errors for methane and carbon dioxide are $0.02 \mathrm{ppm}$ and $4 \mathrm{ppm}$, respectively. These correspond to $1 \%$ error for both methane and carbon dioxide retrievals).

\section{REFERENCES}

[1] http://repository.tksc.jaxa.jp/dr/prc/japan/contents/AA0065136000/6513 6000.pdf?IS_STYLE=jpn( Accessed on September 14 2012)

[2] Clough, S. A., et al. [2006], IEEE Trans. Geosci. Remote Sens., 44, $1308-1323$.

[3] Hase, F., et al. [2004], J. Quant. Spectrosc. Radiat. Transfer, 87(1), 2552.

[4] Rodgers, C. D. [2000], Inverse Methods for Atmospheric Sounding: Theory and Practice.

[5] Tikhonov, A. [1963], Dokl. Acad. Nauk SSSR, 151, 501-504.J. Clerk Maxwell, A Treatise on Electricity and Magnetism, 3rd ed., vol. 2. Oxford: Clarendon, 1892, pp.68-73.

[6] Wunch, D, et al., [2001], The Total Carbon Cloumn Obesrving Network (TCCON), Phil., Tarns. R. Soc. A., 369, 2087-2112.

\section{AUTHORS PROFILE}

Kohei Arai, He received BS, MS and PhD degrees in 1972, 1974 and 1982, respectively. He was with The Institute for Industrial Science, and Technology of the University of Tokyo from 1974 to 1978 also was with National Space Development Agency of Japan (current JAXA) from 1979 to 1990. During from 1985 to 1987, he was with Canada Centre for Remote Sensing as a Post Doctoral Fellow of National Science and Engineering Research Council of Canada. He was appointed professor at Department of Information Science, Saga University in 1990. He was appointed councilor for the Aeronautics and Space related to the Technology Committee of the Ministry of Science and Technology during from 1998 to 2000 . He was also appointed councilor of Saga University from 2002 and 2003 followed by an executive councilor of the Remote Sensing Society of Japan for 2003 to 2005 . He is an adjunct professor of University of Arizona, USA since 1998. He also was appointedvice chairman of the Commission "A" of ICSU/COSPAR in 2008. He wrote 30 books and published 332 journal papers. 